\title{
MARGINAL ADAPTATION AND PERFORMANCE OF BIOACTIVE DENTAL RESTORATIVE MATERIALS IN DECIDUOUS AND YOUNG PERMANENT TEETH
}

\author{
Elizabeta GJORGIEVSKA ${ }^{1}$, John W. NICHOLSON ${ }^{2}$, Snezana ILJOVSKA ${ }^{1}$, Ian J. SLIPPER ${ }^{2}$
}

1- Clinic for Pediatric and Preventive Dentistry, Faculty of Dental Medicine, University "Sts. Kiril and Metodij" Skopje, Republic of Macedonia.

2- School of Science, University of Greenwich at Medway, Medway, Kent, ME4 4TB,UK.

Corresponding address: Professor John W. Nicholson - University of Greenwich at Medway, Kent ME4 4TB, United Kingdom. Phone: 0044(0)208 3319965 - e-mail: J.W.Nicholson@gre.ac.uk

Received: October 30, 2007 - Modification: November 17, 2007 - Accepted: November 23, 2007

\begin{abstract}
$O$

bjective: The aim of this study was to investigate the adaptation of different types of restorations towards deciduous and young permanent teeth. Materials and Methods: Class V cavities were prepared in deciduous and young permanent teeth and filled with different materials (a conventional glass-ionomer, a resin-modified glass-ionomer, a poly-acid-modified composite resin and a conventional composite resin). Specimens were aged in artificial saliva for 1, 6, 12 and 18 months, then examined by SEM. Results: The composite resin and the polyacid-modified composite had better marginal adaptation than the glassionomers, though microcracks developed in the enamel of the tooth. The glass-ionomers showed inferior marginal quality and durability, but no microcracking of the enamel. The margins of the resin-modified glass-ionomer were slightly superior to the conventional glass-ionomer. Conditioning improved the adaptation of the composite resin, but the type of tooth made little or no difference to the performance of the restorative material. All materials were associated with the formation of crystals in the gaps between the filling and the tooth; the quantity and shape of these crystals varied with the material. Conclusions: Resinbased materials are generally better at forming sound, durable margins in deciduous and young permanent teeth than cements, but are associated with microcracks in the enamel. All fluoride-releasing materials give rise to crystalline deposits.
\end{abstract}

Uniterms: Adaptation. Restorative materials. Enamel microcracks. Crystalline deposits.

\section{INTRODUCTION}

In any repair of a tooth with permanent restorative materials, the interface is always a sensitive region. The appearance of adhesive materials was a great step forward in dealing with the problems of this region and improving the overall performance of the restorations ${ }^{11}$. However, contemporary adhesive materials do have a major disadvantage, namely that their durability is limited, a limitation which often arises due to their inadequate marginal adaptation.

The factors that are most commonly attributed to failure are the harsh conditions of the oral environment, such as temperature change, the fatigue of the bond owing to tooth flexure, the presence of bacterial enzymes, and the aqueous environment ${ }^{2}$. Good marginal adaptation decreases microleakage considerably and also reduces the postoperative sensitivity and the occurrence of secondary caries. It thus improves the longevity of the fillings. By contrast, the presence of micro-cracks in the enamel may increase the risk of in-growth of microorganisms and result in caries development ${ }^{4}$.

An important factor in obtaining good marginal adaptation is adhesion to the hard dental tissues (enamel and also dentin $)^{15}$. In the case of composite resins, attachment is achieved through micromechanical adhesion. This involves etching of the surface, a process which produces a porous surface into which the resin-based bonding material is able to penetrate. Adhesion of this type was first reported in 1955 by Buonocore and was concentrated on the enamel ${ }^{1,19}$. Bonding to dentin is much more complicated and the first success in this field was achieved in the early 1980s when Nakabayashi, et al. ${ }^{11}$ prepared hybridized dentin in the subsurface layer in order to obtain an appropriate substrate for adhesion. At the present time, however, clinical practice is moving towards the self-etching, 'all-in-one' adhesives. These are products that combine a single clinical step and reduced postoperative sensitivity ${ }^{16}$.

Finally, there is chemical adhesion, as found with glass 
ionomer cements. These materials are able to form bonds to tooth surfaces, either dentin or enamel as a result of the ion exchange between the cement and the tooth surface ${ }^{10}$. The resulting bond appears to be highly durable. The ionexchange process occurs at the interface between the material and the tooth, and has been attributed to chelation of the calcium ions in the surface of the hydroxyapatite layer by the polyacid of the cement ${ }^{12}$.

The chemistry of glass-ionomers has been incorporated into other modern materials, namely the resin-modified glass ionomer cements (RMGIC) and the polyacid modified composite resins ${ }^{9}$. Of these materials, resin-modified glass ionomer cements (RMGIC) most closely resemble conventional glass ionomer cements ${ }^{18}$ and are capable of setting by an acid-base mechanism. This is supplemented by a free radical polymerization reaction involving the monomer 2-hydroxyethyl methacrylate, HEMA. By contrast, the polyacid-modified composite resins display closer relationship to the composite resins ${ }^{7}$. They consist of substantially the same components as the composite resins, but also include a small amount of acid-functional monomer, and some ionomer glass. They are therefore able to undergo a secondary acid-base reaction on exposure to moisture, and this results in some limited polysalt formation ${ }^{14}$.

In the present study, the extent to which different types of modern restorative materials are capable of forming a marginal seal with the hard dental tissues has been examined. The study was an in vitro one, carried out on extracted teeth and involving a conventional glass ionomer, a resinmodified glass-ionomer, a polyacid modified composite resin and a conventional composite formulated to release fluoride in situ. Marginal adaptation was evaluated, as was the formation of crystalline deposits in the enamel microcracks. Two types of teeth were used, deciduous and young permanent, in order to take account of their variations in structure, morphology and chemical composition.

\section{MATERIALAND METHODS}

Deciduous and permanent teeth were used in this investigation, the deciduous teeth being obtained by exfoliation and the young permanent teeth by extraction for orthodontic reasons. After collection, the tooth surfaces were cleaned, the radices cut with a diamond bur with watercooling to the level of the cemento-enamel junction, and the remnants of the pulpal tissue discarded. Class V cavities were prepared on every tooth using diamond bur and turbine with water-cooling. Then, the teeth were divided into four groups at random and filled with different materials, as listed in Table 1. Each of the groups was divided in two subgroups; the first one was conditioned, and the second was left unconditioned. In the composite group, however all of the specimens were conditioned, since this material is never used clinically without conditioning. For each material/ pretreatment regime, a total of 6 teeth of each type were used, and conditioning and filling were carried out according to the manufacturer's instructions.

The teeth were stored in artificial saliva ${ }^{13}$ as described in British Standard 7115, part 2, BSI, London, 1988. The composition is given in Table 2.

Examinations were undertaken after time intervals of 1 month, 6 months, 12 months and 18 months. Teeth were desiccated, sputter-coated with gold (Edwards 150B) and examined using a high-resolution Scanning Electron Microscope (Stereoscan 360, Cambridge Instruments, Co., $\mathrm{UK}$ ) at low magnification (x40). Qualitative analysis of the enamel margins was performed according to the modification of the criteria given by Dietrich ${ }^{6}$ and involved assessment of (i) marginal excellence, (ii) marginal irregularity, (iii) marginal opening, (iv) fracture of the restoration margin, (v) fracture of the enamel margin, (vi) micro-cracking of enamel, and (vii) loss of restoration.

Representative samples of the teeth stored for 18 months were cut in half and the cut surfaces were placed on the bottom of plastic moulds (Buehler®, USA, Batch No. 208180 ) with $32 \mathrm{~mm}$ internal diameter. The moulds were filled

TABLE 1- Materials used

\begin{tabular}{llll}
\hline Material & Type & Manufacturer & Conditioning option \\
\hline Fuji IX & Conventional GIC & GC, Japan & Cavity conditioner \\
(GC, Japan)
\end{tabular}


with resin (Epo-Thin, Buehler®, USA, Batch No.20-8140032) and cured in a vacuum desiccator for 1 hour. The curing process continued at room temperature for 24 hours. The sample preparation was finished by grinding with different sizes of carborundum grits down to $1 \mu \mathrm{m}$ diamond. The samples were then carbon coated (Model S105, Edwards Co., UK) and examined with JEOL JSM 5310LV Scanning Electron Microscope at 350x magnification with backscattered electron mode $(20 \mathrm{kV}$ accelerating voltage and $15 \mathrm{~mm}$ working distance).

Additionally, SEM analysis of the micro-cracks was performed at higher magnifications (up to x15000), to study the formation of crystals into the gap between the filling and the tooth surface.

TABLE 2- Components of the artificial saliva

\section{Component Concentration $\left(\mathrm{g} \mathrm{l}^{-1}\right)$}

\begin{tabular}{ll}
\hline $\mathrm{NaCl}$ & 0.50 \\
$\mathrm{NaHCO}_{3}$ & 4.20 \\
$\mathrm{NaNO}_{3}$ & 0.03 \\
$\mathrm{KCl}$ & 0.20 \\
\hline
\end{tabular}

\section{RESULTS}

The results for the marginal adaptation and micromorphology are summarised in Table 3. These data were obtained using SEM at low magnification (x 40).

The conventional glass-ionomer cement (Fuji IX) was found to exhibit marginal gaps, and also fractured edges and rough surfaces. The compomer (Dyract AP) and the composite resin (Unifil Flow) were each found to have significantly better margins, but were associated with the appearance of enamel micro-cracks in just over half of the samples.

The behaviour of the resin-modified glass-ionomer (Fuji II LC) was somewhat variable. The conditioned samples had better marginal quality but, like Dyract AP and Unifil Flow, formed micro-cracks in the enamel. The deciduous, unconditioned permanent teeth showed generally open margins and fractured restoration edges.

The SEM images at higher magnification (up to $\mathrm{x}$ 15000) showed the occurrence of crystalline deposits in the gaps between the filling and the tooth surface (Figure 1). The crystals associated with the glass-ionomer cement (Fuji IX) were rounded. At 1 month they were separate, but at later times had coalesced. The crystals formed by Fuji II LC were sparse and isolated, with a polygonal shape and almost no growth as the time passed (Figure 2). The SEM micrographs of the enamel of tooth specimens with Dyract AP fillings after 1 month illustrated only single crystalline formations, but there were conglomerations of them after 12 and 18 months, with triangular, quadrangular and polygonal shape and sharp edges. Finally, the conventional composite (Unifil

TABLE 3- Summary of results for marginal integrity etc

\begin{tabular}{|c|c|c|c|c|}
\hline & Margins (general) & Marginal opening & Marginal fracture & Enamel microcracks \\
\hline Fuji IX & $\begin{array}{l}\text { Poor from } 1 \text { month in all } \\
\text { cases }\end{array}$ & $\begin{array}{l}\text { Present in all cases from } 1 \\
\text { month }\end{array}$ & $\begin{array}{l}\text { Fracture occurred by } 1 \\
\text { month in all cases }\end{array}$ & $\begin{array}{l}\text { No microcracks in enamel in } \\
\text { all cases }\end{array}$ \\
\hline F II LC & $\begin{array}{l}\text { Poor from } 1 \text { month in all } \\
\text { cases }\end{array}$ & $\begin{array}{l}\text { Present in all cases from } 1 \\
\text { month, though some } \\
\text { evidence of closure in older } \\
\text { samples }\end{array}$ & $\begin{array}{l}\text { Some fracturing by } 1 \text { month } \\
\text { in various samples }\end{array}$ & $\begin{array}{l}\text { Enamel microcracks in } \\
\text { deciduous (conditioned) } \\
\text { and permanent } \\
\text { (unconditioned) only by } 6 \\
\text { months }\end{array}$ \\
\hline Dyr. AP & $\begin{array}{l}\text { Poor from } 1 \text { month in all } \\
\text { cases except young } \\
\text { unconditioned, which } \\
\text { became poor by } 6 \text { months }\end{array}$ & $\begin{array}{l}\text { Some opening of margins in } \\
\text { conditioned teeth only after } \\
6 \text { months }\end{array}$ & $\begin{array}{l}\text { Fracture of margins in } \\
\text { samples in conditioned teeth } \\
\text { only after } 6 \text { months }\end{array}$ & $\begin{array}{l}\text { Enamel microcracks } \\
\text { apparent at } 1 \text { month for } \\
\text { permanent (unconditioned) } \\
\text { only; and also in deciduous } \\
\text { (conditioned) and permanent } \\
\text { (conditioned) by } 6 \text { months. } \\
\text { No microcracks in deciduous } \\
\text { (unconditioned) even after } \\
18 \text { months. }\end{array}$ \\
\hline Unifil Fl. & $\begin{array}{l}\text { Excellent in young } \\
\text { permanent teeth, good in } \\
\text { deciduous samples }\end{array}$ & $\begin{array}{l}\text { Complete absence of } \\
\text { marginal opening in all } \\
\text { samples }\end{array}$ & No fracture in any samples & $\begin{array}{l}\text { Microcracks in deciduous at } \\
6 \text { months and permanent at } \\
12 \text { months. }\end{array}$ \\
\hline
\end{tabular}



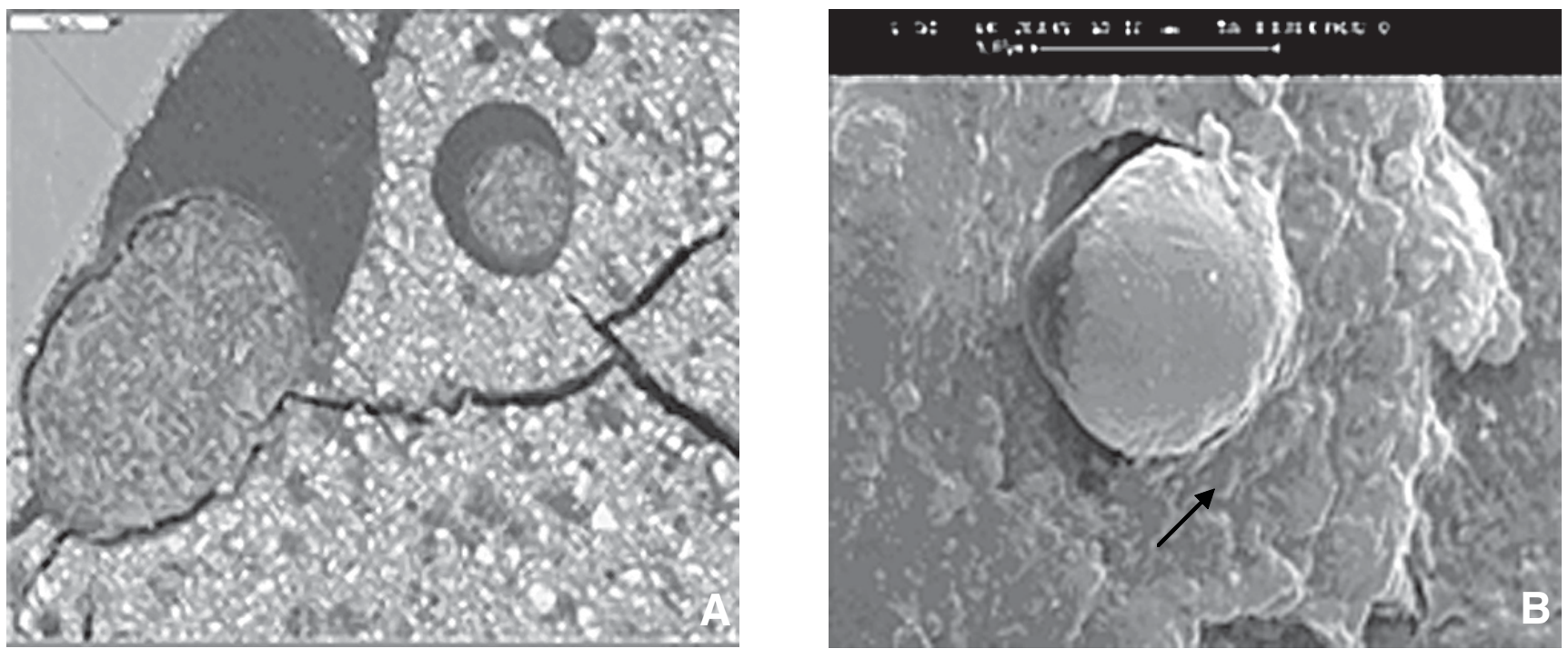

FIGURE 1- Spherical structures formed at the interface between the glass ionomer cement fillings and the tooth after 18 months storage in artificial saliva (magnification: x 15000); A. Fuji II LC resin modified glass ionomer filling, B. Fuji IX conventional glass ionomer. Image dimensions equivalent to 13.5 microns wide $\times 13.5$ microns high

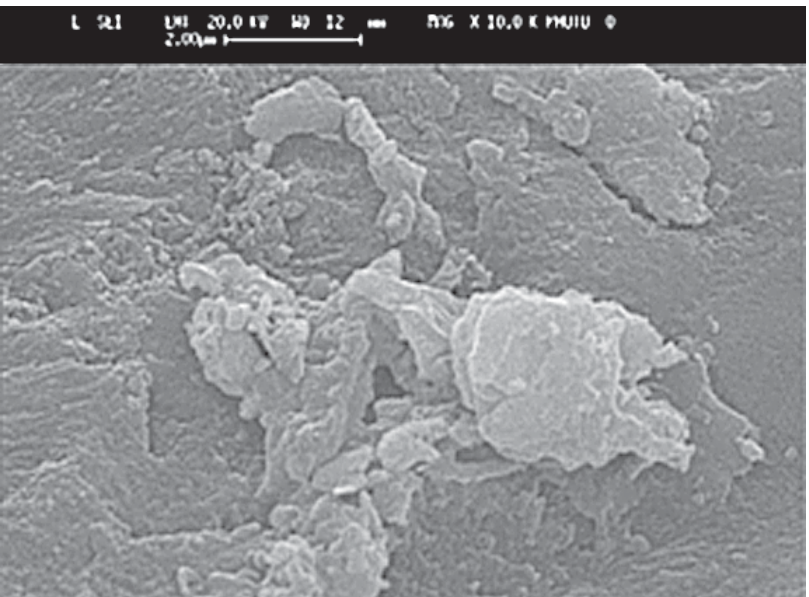

FIGURE 2- Example of deposite on Fuji II LC after 18 months(magnification: $x$ 350). Image dimensions equivalent to 12.0 microns wide $\times 8.0$ microns high

Flow), which is fluoride-releasing, gave rise to long, needleshaped crystals which became progressively more joined after 12 and 18 months (Figure 3).

\section{DISCUSSION}

Deciduous and permanent teeth show considerable differences in the amount and distribution of mineral phase and there are also substantial differences in micro-structure between them. The primary dentin is thinner than that of permanent dentin, and this could be the reason for the lower bond strengths that have been recorded for primary dentin ${ }^{5}$. Tubule density and diameter are also greater for primary teeth, and together these result in a reduced area of intertubular dentin being available for bonding. Chemically, the dentin of primary teeth seems to be more reactive to

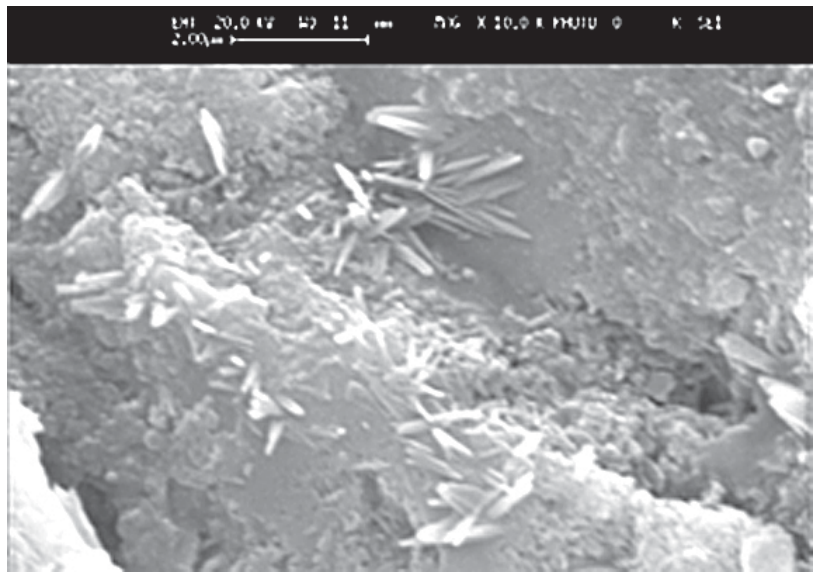

FIGURE 3- Needle-like crystals from Unifil Flow after 18 months (magnification: $x$ 350). Image dimensions equivalent to 12.0 microns wide $\times 7.5$ microns high

acidic conditioners, which could be explained by the reduced degree of mineralization observed for primary hard dental tissues ${ }^{17}$.

On the other hand, the young immature permanent teeth can present obstacles to optimal etching, and hence to satisfactory bonding of composite resin restorations ${ }^{3}$. Factors that contribute to this include the incomplete maturation of enamel, wide dentinal tubules and aprismatic enamel ${ }^{3}$

This present study has shown that the marginal adaptation in deciduous teeth is slightly inferior to that in immature permanent ones, especially when the resin-based materials are used. By contrast, there was no difference between these two types of teeth when conventional glass ionomers were used. Some cracks were visible in the cement under SEM, but this was probably an artifact arising from desiccation during specimen preparation. The resin-modified glass ionomer cement tended to cause cracks adjacent to 
the interfacial region, but not in the material itself ${ }^{8}$, which was again probably due to dessication. Dentin consists of approximately $30 \%$ organic substance, and this contracts during drying, causing the dentin to fracture ${ }^{20}$.

Conditioning the tooth prior to placement of glassionomer cement may inhibit the development of the ion exchange layer. However, leaving the smear layer undisturbed complicates the development of an adhesive layer. In the present study, conditioned samples were found to be better attached to the tooth surface, though this had the adverse effect of causing micro-cracking of the enamel.

The SEM study at higher magnifications showed that all of the restorative materials examined showed the formation of crystals at the interface with the tooth. This may be considered an indication of bioactivity, and is probably associated with fluoride release. In fact, the most bioactive material proved to be the conventional glass ionomer, where after 18 months the whole surface of the enamel deep in the gap next to the material was covered with crystalline deposits having both with globular and spherical forms. The other materials showed some bioactivity, but to a lesser extent than the glass ionomer. In general, the crystals were fewer in number and smaller; in the case of the composite resin, they were needle-shaped. This might be taken as an evidence of the ability of bioactive materials (especially the glassionomers) to repair the gaps between the tooth and the filling. The crystals are probably a result of the ion leaching from the materials, especially fluoride, strontium, calcium and phosphate, and they form the ion enriched layer where the deposits are attached. Their different form is probably due to the variables in their composition (calcium phosphate, calcium fluoride etc), though additional investigation is needed for them to be fully characterised.

\section{CONCLUSIONS}

This study has shown that the resin-based materials (polyacid modified and conventional composite resins) provided better marginal adaptation to both deciduous and immature permanent teeth. However, they were associated with the formation of micro-cracks in the enamel. By contrast, the glass ionomer fillings had open margins, which might be due to desiccation during preparation of the specimens for examination by SEM. Conditioned samples were better adapted to the cavities.

All of the materials studied showed bioactivity, in that they formed crystalline deposits in the gaps between the filling and the tooth. In the case of glass ionomers, such deposits were most numerous, and had a spherical morphology. For polyacid modified composites they were less numerous, but structurally similar. However, for the fluoride-releasing composite, they were needle-like. The full significance of these observations is not clear but merits further study.

\section{ACKNOWLEDGEMENT}

We thank the UK Engineering and Physical Sciences Research Council for the award of a Visiting Fellowship (to EG) which allowed some of the experimental work reported in this paper to be carried out at the University of Greenwich.

\section{REFERENCES}

1- Buonocore MG, A simple method of increasing the adhesion of acrylic materials to enamel surfaces. J Dent Res. 1955;34(6):84953.

2- Burrow MF, Harada N, Kitasako Y, Nikaido T, Tagami J. Sevenyear dentin bond strengths of a total- and self-etch system. Eur J Oral Sci. 2005;113(3):265-70.

3- Celiberti P, Lussi A. Use of a self-etching adhesive on previously etched intact enamel and its effect on sealant microleakage and tag formation. J Dent. 2005;33(2):163-71.

4- Chuang S F, Chang C H, Yaman P, Chang L T. Influence of enamel wetness on resin composite restorations using various dentine bonding agents: Part I - effects on marginal quality and enamel microcrack formation. J Dent. 2005;33(1):1-9.

5- Courson F, Bouter D, Ruse ND, Degrange M. Bond strengths of nine current dentine adhesive systems to primary and permanent teeth. J Oral Rehabil. 2006;32(4):296-303.

6- Dietrich T, Kreamer M, Losche GM, Roulet JF. Marginal integrity of large compomer Class II restorations with cervical margins in dentine. J Dent. 2000;28(6):399-405.

7- Guggenberger R, May R, Stefan KP. New trends in glass-ionomer chemistry. Biomaterials. 1998;19(6):479-83.

8- Mason PN, Ferrari M. In vivo evaluation of glass-ionomer cement adhesion to dentin. Quintessence Int. 1994;25(7):499-504.

9- McLean JW, Nicholson JW, Wilson AD. Proposed nomenclature for glass ionomer cements and related materials. Quintessence Int. 1994;25(9):587-9.

10- Mount GJ, Ngo H. Minimal intervention: a new concept for operative dentistry. Quintessence Int. 2000;31(8):527-33.

11- Nakabayashi N. Dental biomaterials and the healing of dental tissue. Biomaterials. 2003;21(23):2437-9.

12- Nicholson JW. Adhesive dental materials and their durability. Int J Adhes Adhes. 2000;20(1):11-6.

13- Nicholson JW, Amiri MA. The interaction of dental cements with aqueous solutions of varying $\mathrm{pH}$. J Mater Sci Mater Med. 1998;9(10):549-54.

14- Nicholson JW, Gjorgievska E, Bajraktarova B, McKenzie, MA. Changes in properties of polyacid- modified composite resins (compomers) following storage in acidic solutions. J Oral Rehabil. 2003;30(6):601-7.

15- Pereira JC, D’Alpino PHP, Lopes LG, Franco EB, Mondelli RFL, Souza JB de. Evaluation of internal adaptation of class $\mathrm{V}$ resin composite restorations using three techniques of polymerization. J Appl Oral Sci. 2007;15(1):49-54.

16- Pilecki P, Stone DG, Sheriff M, Watson TF. Microtensile bond strengths to enamel of self-etching and one bottle adhesive systems. J Oral Rehabil. 2005;32(7):531-40. 
17- Sardella TN, de Castro FLA, Sanabe ME, Hebling, J, Shortening of primary dentin etching time and its implication on bond strength. J Dent. 2005;33(5):355-62

18- Setien VJ, Armstrong SR, Wefel JS. Interfacial fracture toughness between resin-modified glass ionomer and dentin using three different surface treatments. Dent Mater. 2005;21(6):498-504.

19- Smith DC. Development of glass ionomer cement systems. Biomaterials. 1998;19(6):467-78.

20- Yli-Urpo H, Narhi M, Narhi T. Compound changes and tooth mineralization effects of glass ionomer cements containing bioactive glass (S53P4), an in vivo study. Biomaterials. 2005;26(29):5934-41. 